\title{
Synthesis and Properties of Tetrabenzoporphyrins with Fused $N$-Octylmaleoimide Fragment
}

\author{
Nikolay E. Galanin, ${ }^{\circledR}$ Leonid A. Yakubov, and Gennady P. Shaposhnikov \\ Ivanovo State University of Chemistry and Technology, Friedrich Engels Pr-t, 7, Ivanovo, 153000, Russia \\ ${ }^{\circledR}$ Corresponding authorE-mail: nik-galanin@yandex.ru
}

\begin{abstract}
The reaction of dipotassium salt of pyromellitic acid monoanhydride with hydrazine sulfate leads to 4,5-dicarboxyphthalylhydrazide (1,4-dioxo-1,2,3,4-tetrahydro-6,7-phthalazinedicarboxylic acid) 2, which upon treatment with 1-octylbromide produces a mixture of $N, N$ - and $N, O$ - alkylation products, 2,3-dioctyl-1,4-dioxo1,2,3,4-tetrahydro- and 4-octyloxy-2-octyl-1-oxo-1,2-dihydro-6,7-phthalazinedicarboxylic acids (2 and 3). The acid 2 was converted to imide of 2,3-dioctyl-1,4-dioxo-1,2,3,4-tetrahydro-6,7-phthalazinedicarboxylic acid 4 which upon heating undegoes ring contraction with formation of $N$-octyldiimide of pyromellitic acid 5 and upon co-condensation with phthalimide and in the presence of zinc acetate gives the zinc complex of tetrabenzoporphyrin 6, containing $N$-octyldicarboimide moiety (fused N-octylmaleoimide fragment) in one of benzene rings. Demetallation of the zinc complex 6 upon reprecipitation from conc. sulfuric acid gives the free base porphyrin 7 . Spectral properties of the new compounds have been studied.
\end{abstract}

Keywords: Tetrabenzoporphyrins, imides of pyromellitic acid, 1,4-dioxo-1,2,3,4-tetrahydro-6,7phthalazinedicarboxylic acid, $N, N$ - and $N, O$-alkylation.

\section{Синтез и свойства тетрабензопорфиринов с аннелированным фрагментом $N$-октилмалеоимида}

\author{
Н. Е. Галанин, ${ }^{@}$ Л. А. Якубов, Г. П. Шапошников \\ Ивановский государственный химико-технологический университет, пр-т Ф. Энгельса, 7, Иваново, 153000, Россия \\ @E-mail: nik-galanin@yandex.ru
}

\begin{abstract}
Взаимодействием дикалиевой соли моноангидрида пиромеллитовой кислоты с гидразинсульфатом получен 6,7-дикарбоксифталилгидразид, из которого алкилированием октилбромидом с последующим амидированием синтезирован имид 2,3-диоктил-1,4-диоксо-1,2,3,4-тетрагидро-6,7-фталазиндикарбоновой кислоты. При нагревании его смеси с фталимидом и ацетатом ичинка образуется цฺинковый комплекс тетрабензопорфирина, содержащий аннелированный фрагмент $N$-октилмалеоимида. Деметаллированием полученного комплекса получен порфирин-лиганд. Исследованы спектральные свойства синтезированных соединений.
\end{abstract}

Ключевые слова: Тетрабензопорфирины, имиды пиромеллитовой кислоты, 1.4-диоксо-1,2,3,4-тетрагидро6,7-фталазиндикарбоновая кислота, $N, N$ - и $N, O$-алкилирование.

\section{Введение}

Важной группой тетрапиррольных макрогетероциклов являются порфиразины, аннелированные гетероциклическими фрагментами..$^{[1-3]}$ Среди них особый интерес представляют соединения несимметричного строения с поляризованной $\pi$-системой, являющиеся перспективными материалами для нелинейной оптики. ${ }^{[4,5]}$ К настоящему времени синтезировано большое количество несимметричных порфиразинов, фталоцианинов и порфиринов ${ }^{[6-9]}$ различного строения с аннелированными гетероциклами. Порфирины с аннелированными гетероциклическими остатками могут найти применение в качестве активных материалов в солнечной энергетике. ${ }^{[10]}$ Поэтому, разработка методов получения и исследование свойств новых тетрабензопорфиринов, содержащих аннелированные гетероциклические фрагменты, являются актуальными задачами.

Не менее интересной группой гетероциклов являются производные фталилгидразида. Некоторые 
из этих соединений обладают биологической активностью (например, действующим началом иммуномодулятора «Галавит» является 5-амино1,2,3,4-тетрагидрофталазин-1,4-дион), используются в качестве люминофоров. В этой связи, исследования производных фталилгидразидов также актуальны.

\section{Экспериментальная часть}

Электронные спектры поглощения полученных соединений измерены на спектрофотометре Hitachi UV-2001, ИК спектры - на спектрофотометре Avatar 360 FT-IR в области $400-4000 \mathrm{~cm}^{-1}$ в тонких пленках и в таблетках с $\mathrm{KBr}$, спектры ${ }^{1} \mathrm{H}$ ЯМР в $\mathrm{CDCl}_{3}$ и ДМСО- $d_{6}$ (внутренний стандарт ГМДС) - на приборах Bruker AMD-200 и Bruker Avance-500, массспектры (матрица - -нитробензиловый спирт) зарегистрированы на масс-спектрометре JEOL JMS 700. Элементный анализ выполнен на приборе FlashEA 1112 CHNS-O Analyzer.

4,5-Дикарбоксифталилгидразид [1,4-диоксо-1,2,3,4тетрагидро-6,7-фталазиндикарбоновая кислота], моногидрат, 1. К суспензии пиромеллитового диангидрида (100 г, 0,46 моль) в 250 мл воды при интенсивном перемешивании в течение 2 ч добавляли порциями по 2 мл раствор карбоната калия (63 г, 0,46 моль) в 200 мл воды, после чего приливали раствор солянокислого гидразина (63 г, 0,92 моль) в 200 мл воды и кипятили в течение 5 часов. Выпавший осадок отфильтровывали, растворяли в 2 л $5 \%$ раствора $\mathrm{NaOH}$ и осаждали соединение 1 добавлением 0,5 л концентрированной соляной кислоты. Осадок отфильтровывали, промывали 200 мл воды и высушивали. Выход 82 г (71\%). Порошок белого цвета, растворим в растворах щелочей, ДМФА, ДМСО, не растворим в воде и растворах минеральных кислот. ИК $(\mathrm{KBr}) \vee \mathrm{cm}^{-1}: 3592$, 3455, 3063, 1712, 1681, 1632, 1593, 1503, 1311, 1268, 1129, 802, 617, 458. 'Н ЯМР (ДМСО- $d_{6}$ ) $\delta$ м.д.: 9,70 (с., $\left.2 \mathrm{H}, \mathrm{NH}\right), 8,27$ (с., $2 \mathrm{H}$, $\mathrm{C}_{\mathrm{Ar}}-H$ ). Найдено, \%: С 44,76; Н 3,21; N 10,57. $\mathrm{C}_{10} \mathrm{H}_{6} \mathrm{~N}_{2} \mathrm{O}_{6} \cdot \mathrm{H}_{2} \mathrm{O}$. Вычислено, \%: С 44,79; Н 3,01; N 10,45.

Алкилирование моногидрата 4,5-дикарбоксифталилгидразида. Смесь кислоты 1 (5,4 г, 0,02 моль), 1-октилбромида (8,0 г, 0,04 моль), карбоната калия (15 г, 0,1 моль) в 60 мл ДМФА кипятили 10 часов, затем выливали в 300 мл $10 \%$ раствора соляной кислоты. Органический слой отделяли и отгоняли из него непрореагировавший 1-октилбромид с водяным паром. Остаток экстрагировали 30 мл хлороформа, из экстракта отгоняли растворитель. Остаток растворяли в хлороформе и хроматографировали на силикагеле 60 (элюент - хлороформ-ацетон-пиридин, 10:10:1), собирая основную (вторую) желтую зону. После удаления растворителя остаток растворяли в хлороформе и хроматографировали повторно (силикагель 60, элюент - хлороформ-ацетон-пиридин, 30:5:1). Происходило разделение смеси на две зоны светло-желтого цвета, содержащих соответственно:

2,3-Диоктил-1,4-диоксо-1,2,3,4-тетрагидро-6,7фталазиндикарбоновую кислоту, 2. Выход 2,3 г (23\%), вещество светло-желтого цвета, растворимо в бензоле, хлороформе, ДМФА, не растворимо в водных растворах кислот и щелочей. $R_{\mathrm{f}} 0,52\left(\mathrm{CHCl}_{3}\right.$, Silufol). ЭСП $\left(\mathrm{CHCl}_{3}+10 \% \mathrm{C}_{5} \mathrm{H}_{5} \mathrm{~N}\right) \lambda_{\text {макс. }}$ нм: 382 , 372. ИК $\vee \mathrm{cm}^{-1}: 2956,2929,2848,1722,1659,1531,1463,1335,1271$, 775. ${ }^{1} \mathrm{H}$ ЯMР $\left(\mathrm{CDCl}_{3}\right) \delta$ м.д.: 10,65 (уш.с. $\left.2 \mathrm{H}, \mathrm{COOH}\right), 8,63-8,55$ (м., 2H, $\mathrm{C}_{\mathrm{Ar}}-\mathrm{H}$ ), 3,28-3,24 (м., 4H, $\left.\alpha-\mathrm{CH}_{2}\right), 1,80-1,76$ (м., $4 \mathrm{H}, \beta-\mathrm{CH}_{2}$ ), 1,25-1, 15 (м., 20H, $\mathrm{CH}_{2}$ ), 0,88 (м., 6Н, С , $_{3}$. Найдено, \%: С 65,99; Н 8,$21 ; \mathrm{N} 5,81 . \mathrm{C}_{26} \mathrm{H}_{38} \mathrm{~N}_{2} \mathrm{O}_{6}$. Вычислено, \%: С 65,80; Н 8,07; N 5,90.

4-Октилокси-2-октил-1-оксо-1,2-дигидро-6,7фталазиндикарбоновую кислоту, 3. Выход 2,1 г (21\%), вещество светло-желтого цвета, растворимо в бензоле, хлороформе, ДМФА, не растворимо в водных растворах кислот и щелочей. $R_{\mathrm{f}} 0,38\left(\mathrm{CHCl}_{3}\right.$, Silufol). ЭСП $\left(\mathrm{CHCl}_{3}+10 \% \mathrm{C}_{5} \mathrm{H}_{5} \mathrm{~N}\right)$ $\lambda$ нм: 356,349 . ИК $\vee \mathrm{cm}^{-1}: 2955,2926,2856,1718,1658,1525$, $1468,1336,1121,1081,776 .{ }^{1} \mathrm{H}$ ЯMР $\left(\mathrm{CDCl}_{3}\right) \delta$ м.д.: 10,77 (м., 2Н, $\mathrm{COOH}$ ), 9,08 (м., $1 \mathrm{H}, \mathrm{C}_{\mathrm{Ar}}-H$ ), 8,22 (м., $1 \mathrm{H}, \mathrm{C}_{\mathrm{Ar}}-H$ ), 4,36 (м., 2H, $\mathrm{N}-\mathrm{CH}_{2}$ ), 3,12 (м., 2H, O-CH$)_{2}$ ), 1,77 (м., $4 \mathrm{H}, \beta, \beta-\mathrm{CH}_{2}$ ), 1,25 (м., $20 \mathrm{H}, \mathrm{CH}_{2}$ ), 0,84 (м., 6Н, $\mathrm{CH}_{3}$ ). Найдено, \%: С 66,12; Н 8,00; N 5,66. $\mathrm{C}_{26} \mathrm{H}_{38} \mathrm{~N}_{2} \mathrm{O}_{6}$. Вычислено, \%: С 65,80; Н 8,07; N 5,90.

Имид 2,3-диоктил-1,4-диоксо-1,2,3,4-тетрагидро-6,7фталазиндикарбоновой кислоты, 4. Раствор 2,3-диоктил-1,4диоксо-1,2,3,4-тетрагидро-6,7-фталазиндикарбоновой кислоты (2) (2,0 г, 0,004 моль) и ацетата аммония (1,2 г, 0,016 моль) в 10 мл ледяной уксусной кислоты кипятили 4 ч, выливали в 20 мл воды и экстрагировали 10 мл хлороформа. Экстракт упаривали. Выход 1,5 г (77\%). Воскообразное вещество светложелтого цвета, растворимо в бензоле, хлороформе, ДМФА. ИК $\vee$ см$^{-1}: 3420,3168,2924,2854,1731,1666,1594,1556,1465$, $1356,1271,1121,960,817,724,659 .{ }^{~}{ }^{H}$ ЯМР $\left(\mathrm{CDCl}_{3}\right) \delta$ м.д.: 11,22 (с., $1 \mathrm{H}, \mathrm{N} H$ ), 8,71 (м., 2H, $\mathrm{C}_{\mathrm{Ar}}-\mathrm{H}$ ), 3,29 (м., 4H, $\alpha-\mathrm{CH}_{2}$ ), 1,75 (м., $\left.4 \mathrm{H}, \beta-\mathrm{CH}_{2}\right), 1,23$ (м., 20H, $\mathrm{CH}_{2}$ ), 0,88 (м., $6 \mathrm{H}, \mathrm{CH}_{3}$ ). Масс-спектр (FAB), m/z: 456,4 [M+1] $]^{+}$Найдено, \%: С 69,13; Н 8,44; N 8,96. $\mathrm{C}_{26} \mathrm{H}_{37} \mathrm{~N}_{3} \mathrm{O}_{4}$. Вычислено, \%: С 68,54; Н 8,19; $\mathrm{N} 9,22$.

$\mathrm{N}$-Октилдиимид пиромеллитовой кислоты, 5. 0,2 г имида 4 нагревали при $150^{\circ} \mathrm{C}$ в течение 2 ч, после чего остаток растворяли в хлороформе и хроматографировали на силикагеле 60 (элюент - хлороформ-ацетон, 1:1), собирая основную желтую зону. Выход 0,08 г (57\%). Вещество желтого цвета, растворимо в бензоле, хлороформе, ацетоне. ${ }^{1} \mathrm{H}$ ЯМР $\left(\mathrm{CDCl}_{3}\right)$ $\delta$ м.д.: 11,24 (с., $1 \mathrm{H}, \mathrm{NH}), 8,90$ (с., $2 \mathrm{H}, \mathrm{CH}_{\mathrm{Ar}}$ ), 3,20 (м., 2H, N-CH${ }_{2}$ ), 2,02 (м., 2H, $\beta-\mathrm{CH}_{2}$ ), 1,35-1,27 (м., 10H, $\mathrm{CH}_{2}$ ), 0,88 (м., 3Н, $\mathrm{CH}_{3}$ ). Найдено, \%: С 66,18; Н 6,88; N 8,17. $\mathrm{C}_{18} \mathrm{H}_{20} \mathrm{~N}_{2} \mathrm{O}_{4}$. Вычислено, \%: C 65,84; Н 6,14; N 8,53.

Моно [5,6-(2-октил-1,3-диоксоизоиндолино]трибензопорфиринат ичинка, б. Смесь имида 4 (1 г, 2 ммоль), фталимида (2 г, 14 ммоль) и дигидрата ацетата цинка (3 г, 13,5 ммоль) нагревали до $310^{\circ} \mathrm{C}$ и выдерживали 1,5 ч, после чего реакционную массу охлаждали и экстрагировали хлороформом в аппарате Сокслета. Экстракт хроматографировали на оксиде алюминия II степени активности (элюент - хлороформ), собирая основную зеленую зону. Выход 0,11 г (9\%), порошок темно-зеленого цвета, хорошо растворим в бензоле, хлороформе, ацетоне, ДМФА. ЭСП (бензол) $\lambda_{\text {макс }}$ нм (lg $\varepsilon): 401(4,68), 427(5,12), 456(4,60), 579(4,15), 626(4,73)$, $668(3,91)$. ИК $\vee$ см$^{-1}: 3208,3075,2926,2854,1697,1615,1467$, 1359, 1141, 1017, 759, 698. 'Н ЯМР $\left(\mathrm{CDCl}_{3}\right) \delta$ м.д.: 10,21 (с., 2H, мезо-H), 10,18 (с., 2H, мезо-H), 8,23 (с., 2H, $\mathrm{CH}_{\mathrm{Ar}}$ ), 7,75 (с., 4H, $\mathrm{CH}_{\mathrm{Ar}}$ ), 7,49 (с., $2 \mathrm{H}, \mathrm{CH}_{\mathrm{Ar}}$ ), 7,42-7,39 (м., 6H, $\mathrm{CH}_{\mathrm{Ar}}$ ), 3,67 (м., 2H, $\mathrm{N}-\mathrm{CH}_{2}$ ), 2,20 (м., $2 \mathrm{H}, \beta-\mathrm{CH}_{2}$ ), 1,63-1,38 (м., 10H, $\mathrm{CH}_{2}$ ), 0,89-0,86 (м., 3Н, $\mathrm{CH}_{3}$ ). Масс-спектр (FAB), m/z: 755,6 [M+H] $]^{+}$Найдено, \%: С 74,01; Н 5,04; N 8,81. $\mathrm{C}_{46} \mathrm{H}_{35} \mathrm{~N}_{5} \mathrm{O}_{2} \mathrm{Zn}$. Вычислено, \%: С 73,16; H 4,67; N 9,27.

Моно[5,6-(2-октил-1,3-диоксоизоиндолино]трибензопорфирин, 7. Металлокомплекс $6(0,1$ г) растворяли в 10 мл конц. $\mathrm{H}_{2} \mathrm{SO}_{4}$, выдерживали 2 ч при $20^{\circ} \mathrm{C}$, выливали в 50 мл воды, добавляли 50 мл $25 \%$ раствора аммиака и экстрагировали 20 мл хлороформа. Экстракт хроматографировали на оксиде алюминия II степени активности (элюент - хлороформ), собирая основную зеленую зону. Выход 0,05 г (54\%), порошок темно-зеленого цвета, хорошо растворим в бензоле, хлороформе, ацетоне, ДМФА. ЭСП (бензол) $\lambda_{\text {макс }}$ нм $(\lg \varepsilon): 412$ (4,93), $428(4,95), 568(4,12), 598(4,37), 609(4,40), 612(4,36)$, 661 (4,23). Найдено, \%: С 79,65; Н 5,44; N 9,68. C ${ }_{46} \mathrm{H}_{35} \mathrm{~N}_{5} \mathrm{O}_{2} \mathrm{Zn}$. Вычислено, \%: С 79,16; Н 5,39; N 10,12.

\section{Результаты и обсуждение}

Одним из важнейших свойств тетрапиррольных макрогетероциклических соединений, облегчающих их выделение в индивидуальном виде, способствующих 


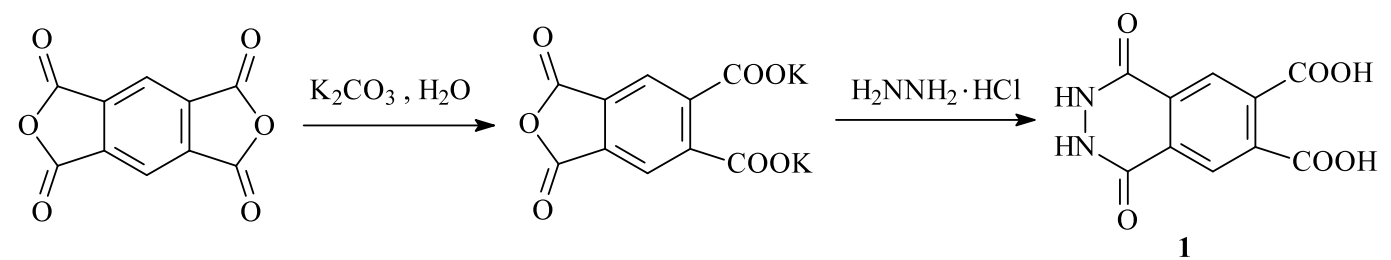

Схема 1.<smiles>O=C(O)c1cc2c(=O)[nH][nH]c(=O)c2cc1C(=O)O</smiles>

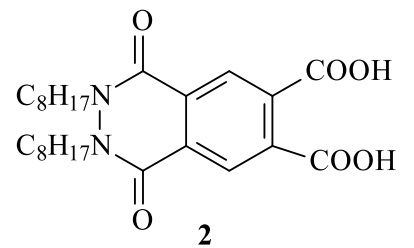

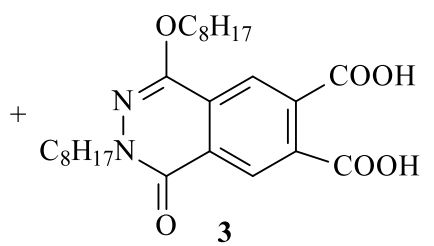

Схема 2.

установлению структуры и расширяющих возможности практического применения, является их растворимость в органических средах. В ряду порфиразинов с аннелированными гетероциклами повышенной растворимости можно достичь введением гидрофобных заместителей или в изоиндольные фрагменты, ${ }^{[1]]}$ или в состав гетероцикла. ${ }^{[5]}$ Последнее предпочтительнее, поскольку наличие в составе гетероциклических фрагментов заместителей, придающих порфиразинам растворимость, позволяет получать органорастворимые соединения как симметричного, так и несимметричного строения. Однако информация о тетрабензопорфиринах подобного типа, т.е. имеющих аннелированные гетероциклы, содержащие объемные гидрофобные заместители, в литературе не обнаружена.

В этой связи, целью настоящей работы явилась разработка метода синтеза имида 2,3-диоктил-1,4диоксо-1,2,3,4-тетрагидро-6,7-фталазиндикарбоновой кислоты и, с его использованием, тетрабензопорфиринов, содержащих аннелированные гетероциклические фрагменты с $\boldsymbol{H}$-октильными заместителями.

На первом этапе работы, взаимодействием моноангидрида дикалиевой соли пиромеллитовой кислоты, полученным частичным гидролизом пиромеллитового диангидрида, с солянокислым гидразином в соответствии со Схемой 1 был получен 4,5-дикарбоксифталилгидразид (1).

Соединение 1 представляет собой белый порошок, растворимый в водных растворах щелочей и полярных органических растворителях. Его строение подтверждали данными элементного анализа, ИК и ${ }^{1} \mathrm{H}$ ЯМР спектроскопии.

В ИК спектре кислоты 1 присутствует полоса при $3453 \mathrm{~cm}^{-1}$, соответствующая колебаниям связей $\mathrm{N}-\mathrm{H}$, и полоса при $1711 \mathrm{~cm}^{-1}$, характеризующая колебания карбонильных групп. '

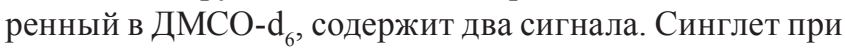
9,70 м.д. соответствует резонансу двух протонов групп $\mathrm{N}-\mathrm{H}$, а синглет при 8,27 м.д. характеризует резонанс двух протонов бензольного кольца. Резонанс протонов карбоксильных групп в спектре не обнаружен, что связано, очевидно, с процессами дейтерообмена.

На втором этапе работы было осуществлено алкилирование соединения 1 1-октиломбромидом.
Известно, что фталилгидразиды могут образовывать продукты как $N$-, так и $O$-алкилирования,, ${ }^{[12,13]}$ причем в высокоосновных средах преобладают последние. В малоосновных средах следует ожидать увеличения содержания продуктов $N$-алкилирования. Однако при попытке алкилирования соединения 1 в отсутствии основных реагентов был получен отрицательный результат. В результате процесса были получены только продукты моноалкилирования в следовых количествах. Поэтому, алкилирование кислоты 1 проводили в ДМФА при температуре кипения в течение 10 ч в присутствии $\mathrm{K}_{2} \mathrm{CO}_{3}$. Как и следовало ожидать, в результате были получены, в основном, два продукта - 2,3-диоктил-1,4-диоксо-1,2,3,4тетрагидро-6,7-фталазиндикарбоновая кислота (2) и изомерная ей 4-дктилокси-2-октил-1-оксо-1,2-дигидро6,7-фталаз-индикарбоновая кислота (3) (Схема 2).

Соединения 2 и 3 были разделены хроматографированием, причем оказалось, что в смеси они содержатся примерно в равных количествах. Кислоты 2 и 3 представляют собой вещества светло-желтого цвета, заметно различающиеся по своим спектральным характеристикам.

Так, электронный спектр поглощения соединения 2 (Рисунок 1,1$)$ в хлороформе с добавкой 10\% пиридина характеризуется широкой полосой с максимумами при 382 и 372 нм, которые в спектре соединения 3 (Рисунок $1,2)$ сдвигаются гипсохромно соответственно на 26 и 23 нм.

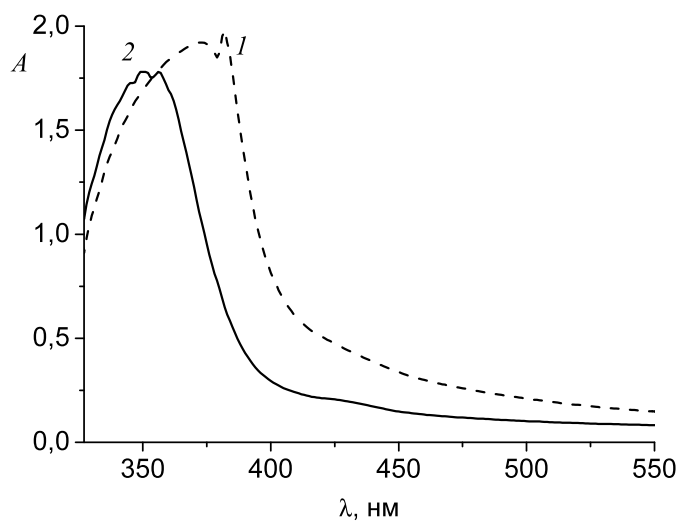

Рисунок 1. Электронные спектры поглощения. 1 - соединение 2, 2 - соединение 3 . 


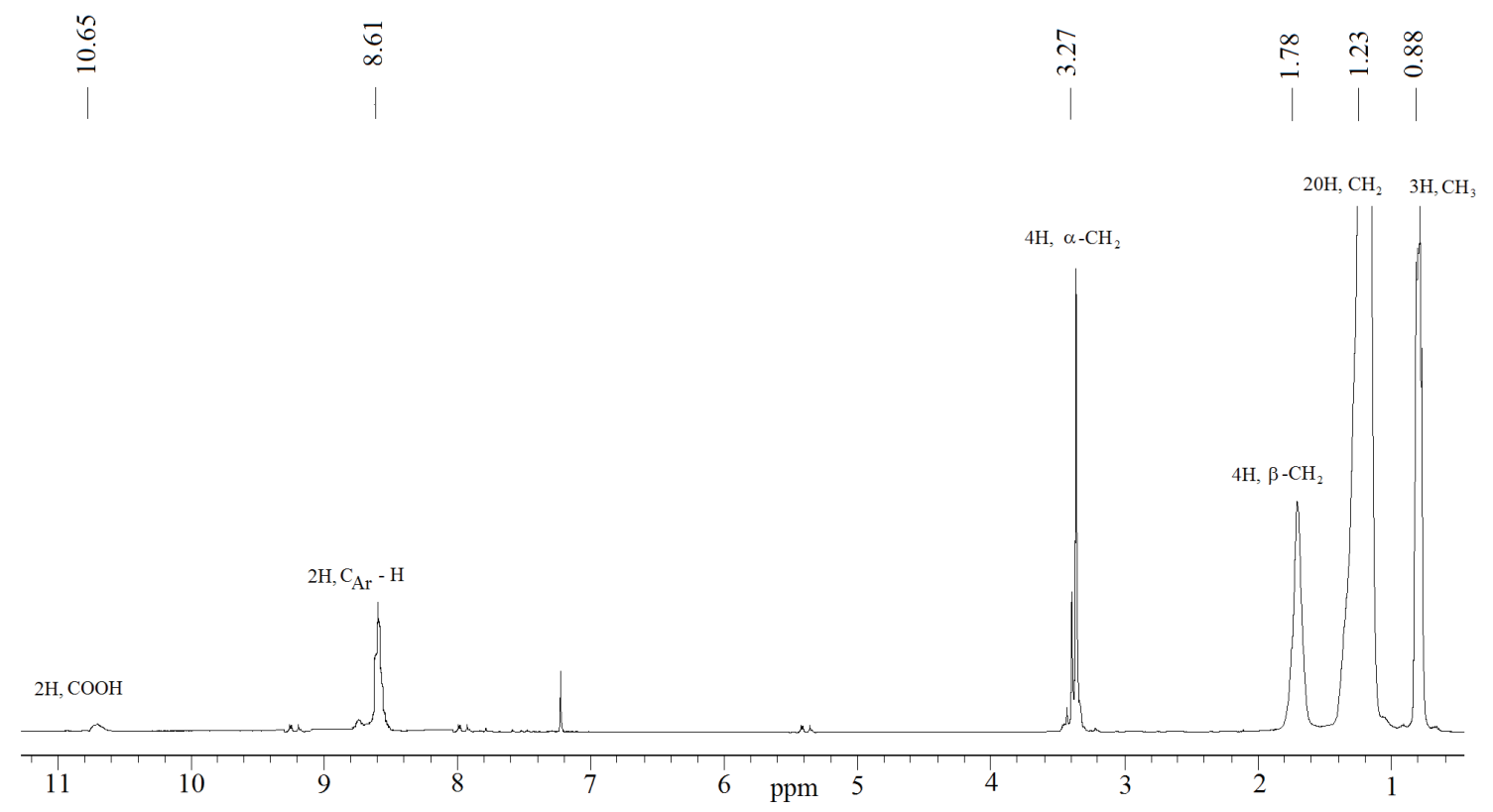

Рисунок 2. ${ }^{1} \mathrm{H}$ ЯМР спектр соединения 2 в $\mathrm{CDCl}_{3}$.

Гипсохромный сдвиг максимумов полос обусловлен, вероятно, более низкой полярностью молекулы 3. Так, ее дипольный момент, вычисленный с использованием метода AM1, составляет 3,067 D, тогда как в случае соединения 2 он составляет 4,326 D.

${ }^{1} \mathrm{H}$ ЯМР спектр кислоты 2 (Рисунок 2) содержит сигнал двух протонов карбоксильных групп в области 10,65 м.д., Двух протонов бензольного кольца, и четыре группы сигналов, характеризующих резонанс 34 протонов двух алкильных заместителей.

Характерно, что сигналы, соответствующие резонансу двух протонов бензольного кольца и четырех протонов $\alpha$-метиленовых групп алкильных заместителей, находятся в виде единичных мультиплетов в области 8,61 и 3,27 м.д. соответственно.

Спектр ЯМР ${ }^{1} \mathrm{H}$ кислоты 3 более сложен. В силу несимметричности ее молекулы сигналы протонов бензольного кольца в виде двух мультиплетов находятся при 9,08 и 8,22 м.д., а резонанс протонов $\alpha$-метиленовых групп также в виде двух мультиплетов зарегистрирован в области 4,36 и 3,12 м.д.

Таким образом, установлено, что в результате алкилирования 4,5-дикарбоксифталилгидразида 1-октилбромидом в ДМФА в присутствии карбоната калия при температуре кипения реакционной массы в течение 10 ч образуются два продукта - N,N- (2) и N,O- (3) диалкилпроизводные в соотношении примерно 1:1.
Кипячением раствора кислоты 2 и избытка ацетата аммония в уксусной кислоте в течение 4 ч был получен имид 2,3-диоктил-1,4-диоксо-1,2,3,4-тетрагидро-6,7фталазиндикарбоновой кислоты (4) (Схема 3).

Соединение 4 представляет собой воскообразное вещество желтого цвета, хорошо растворимое в бензоле, хлороформе, ДМФА. Его строение подтверждено данными элементного анализа, ИК и ${ }^{1} \mathrm{H}$ ЯМР спектроскопии, а также масс-спектрометрии.

В ИК спектре имида 4 присутствует полоса при $3420 \mathrm{~cm}^{-1}$, соответствующая колебаниям связи $\mathrm{N}-\mathrm{H}$, и полоса при $1731 \mathrm{~cm}^{-1}$, характеризующая колебания карбонильных групп. Полосы, соответствующие колебаниям связей C-Н алкильных заместителей, находятся в области 2924-2854 и $1465 \mathrm{~cm}^{-1}$.

В масс-спектре (FAB) соединения 4 (Рисунок 3) отмечен сигнал средней интенсивности с $\mathrm{m} / \mathrm{z} 456,4$, соответствующий протонированному молекулярному иону.

Что касается ${ }^{1} \mathrm{H}$ ЯМР спектра соединения 4, то в нем в наиболее слабом поле отмечен сигнал протона имидного цикла при 11,22 м.д., сигнал двух протонов бензольного кольца находится в области 8,71 м.д., а сигнал четырех протонов двух $\alpha$-метиленовых групп алкильных заместителей зарегистрирован при 3,29 м.д.

Попытка синтеза тетрабензопорфиринов нагреванием соединения 4 с ацетатом цинка по методу [14]

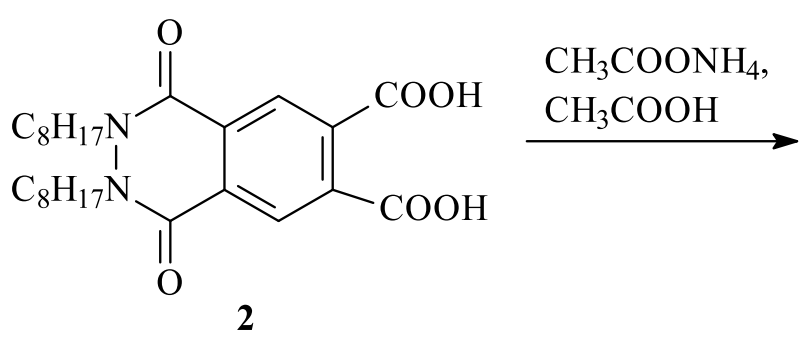

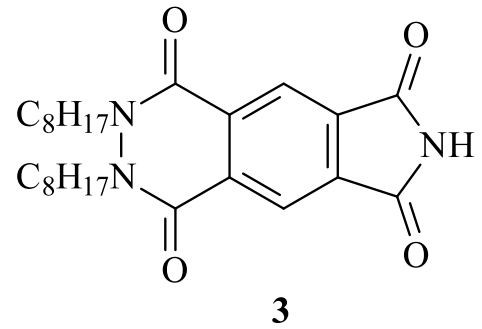

Схема 3. 


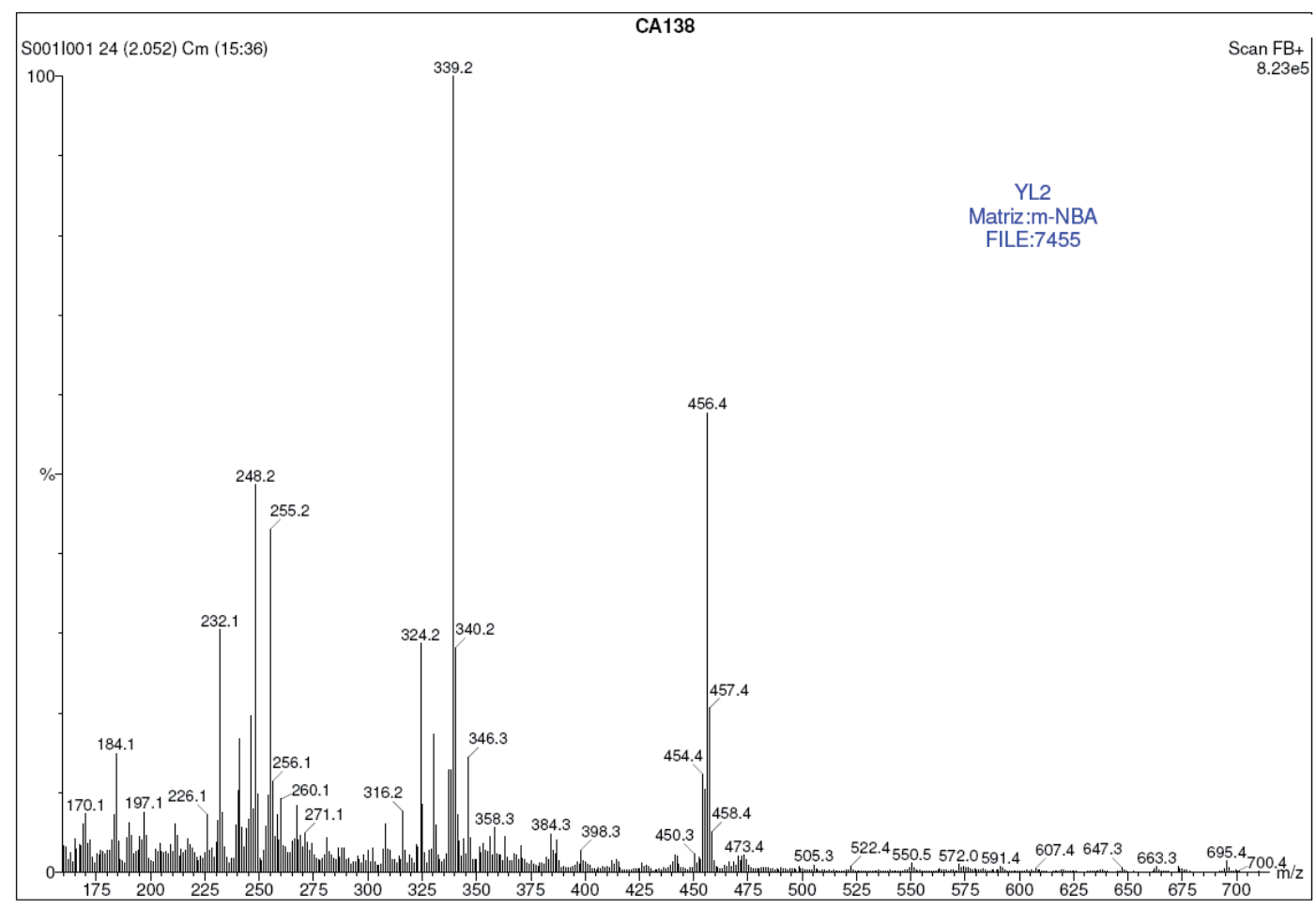

Рисунок 3. Масс-спектр (FAB) соединения 4.

оказалась безуспешной, поскольку не удалось достичь температуры, необходимой для протекания реакции $\left(320-350^{\circ} \mathrm{C}\right)$. Температура кипения реакционной массы не превышала $230^{\circ} \mathrm{C}$, а длительная выдержка (10 ч) приводила к ее осмолению. Причиной столь низкой температуры кипения может служить наличие в реакционной массе октиламина, который, как будет показано далее, образуется в результате химических превращений соединения 4. Поэтому, для получения тетрабензопорфиринов использовали смесь соединения $\mathbf{4}$ с избытками фталимида и ацетата цинка. В этих условиях температура кипения реакционной массы достигает $310^{\circ} \mathrm{C}$, что связано с уменьшением содержания октиламина и его более быстрым испарением. Известно, что повысить температуру реакции можно при применении фталимида калия. ${ }^{[15]}$ Однако в данном случае использование калиевого производного соединения $\mathbf{4}$ или добавление в реакционную массу гидроксида калия не привела к желаемому результату, поскольку в жестких условиях в присутствии щелочей происходит, очевидно, гидролиз алкилимидного цикла соединения $\mathbf{5}$ с образованием остатка фталевой кислоты, неустойчивого при высоких температурах, и в результате процессов реакционная масса осмоляется.

Мы ожидали, что в результате реакции образуется смесь цинковых комплексов тетрабензопорфиринов с различным числом аннелированных гетероциклов. Однако при хроматографическом разделении реакционной массы было обнаружено, что в ней присутствует только одно соединение порфириновой природы, обладающее повышенной растворимостью в органических растворителях. Это соединение было охарактеризовано в дальнейшем как моно[5,6-(2-октил- $1 H$-изоиндол1,3(2H)-дионо]трибензопорфиринат цинка (6). Отсутствие в составе реакционной массы заметных количеств порфиринов с большим числом аннелированных фрагментов $N$-октилмалеоимида можно объяснить значительным избытком незамещенного фталимида.

Очевидно, в условиях проведения процесса происходит термодинамически выгодное сжатие фталазинового гетероцикла молекулы 4 с отщеплением молекулы октиламина. Образующийся in situ

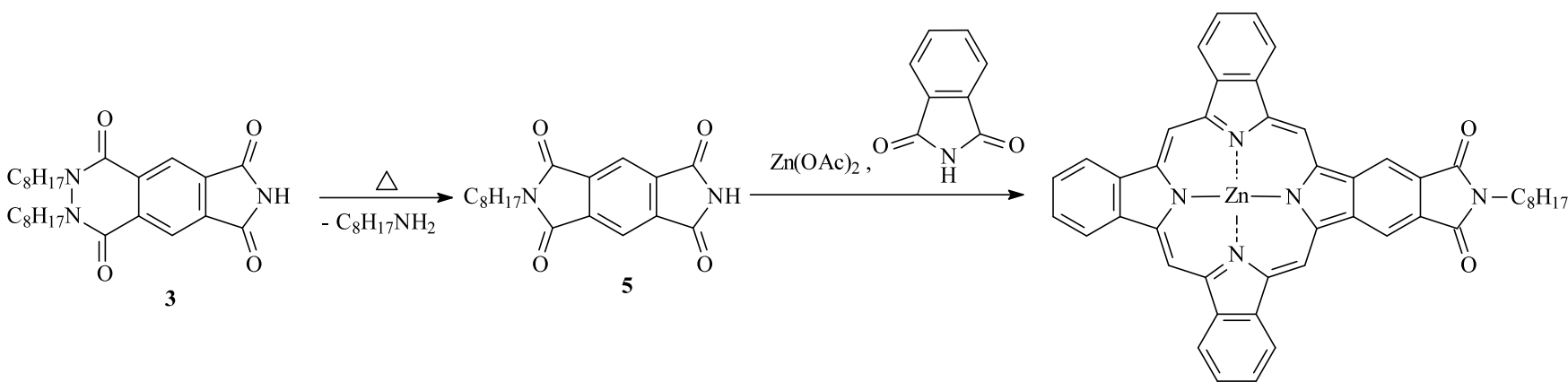

Схема 4. 


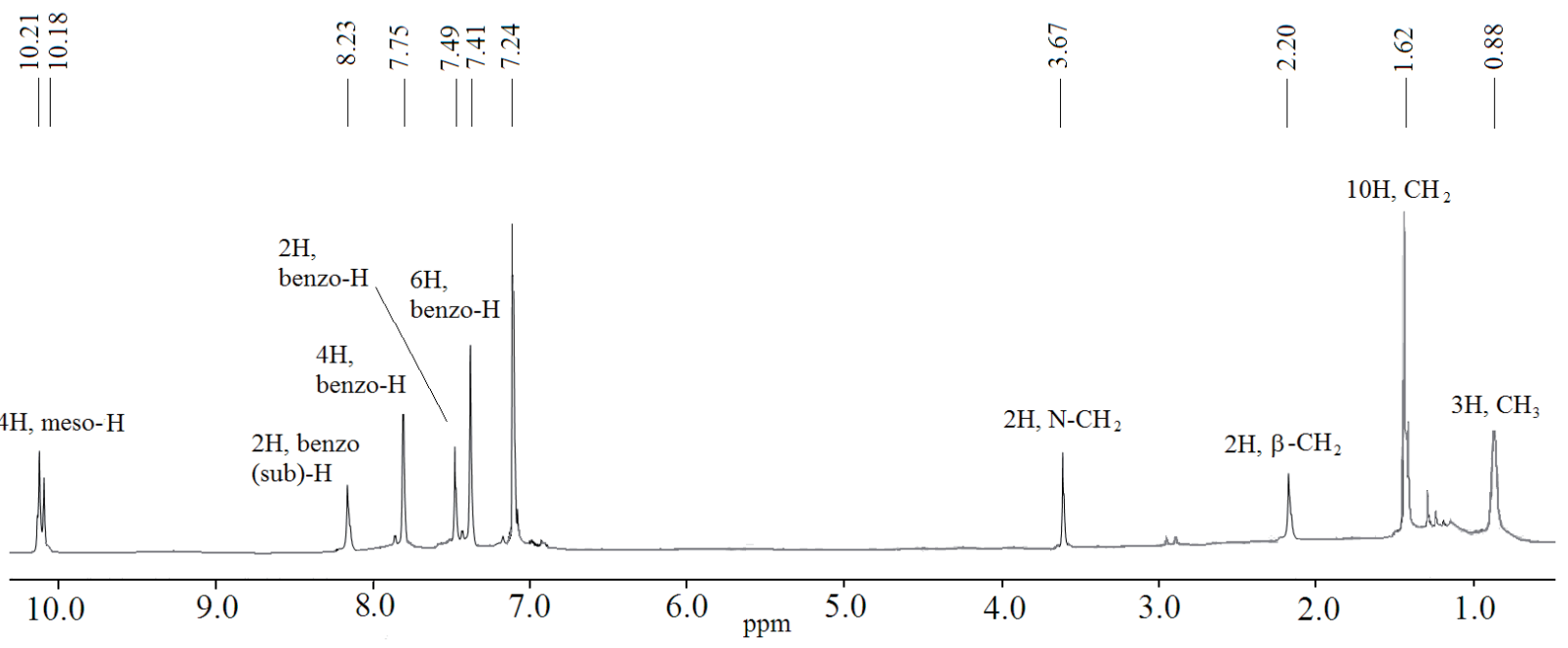

Рисунок 4. ${ }^{1} \mathrm{H}$ ЯМР спектр комплекса 6 в $\mathrm{CDCl}_{3}$.

моно- $N$-октилдиимид пиромеллитовой кислоты 5 вступает затем в реакцию соконденсации с незамещенным фталимидом и ацетат-ионом, с образованием цинкового комплекса 6 в соответствии со Схемой 4.

Подтверждением Схемы 4 может служить тот факт, что нагревание имида 4 при температуре $150{ }^{\circ} \mathrm{C}$ в течение 2 ч действительно приводит к образованию соединения 5 с выходом более $50 \%$.

Порфирин 6 представляет собой порошок темнозеленого цвета, хорошо растворимый в широком ряду органических растворителей. Его строение подтверждено данными элементного анализа, масс-спектрометрии, ${ }^{1} \mathrm{H}$ ЯМР (Рисунок 4), колебательной и электронной спектроскопии.

Как видно из Рисунка 4, в спектре ${ }^{1} \mathrm{H}$ ЯМР порфирина 4 в наиболее слабом поле находятся два синглета, характеризующие резонанс четырех мезопротонов, в области 8,23-7,39 м.д. присутствуют четыре сигнала, соответствующие резонансу 14 протонов бензольных колец, мультиплет в области 3,67 м.д. характеризует резонанс двух протонов $\alpha$-метиленовой группы алкильного заместителя, мультиплет при 2,20 м.д. - Двух протонов $\beta$-метиленовой группы, мультиплет в области 1,63-1,38 м.д. соответствует резонансу 10 протонов пяти концевых метиленовых групп, и, наконец, мультиплет в области 0,88 м.д. характеризует резонанс трех протонов концевой метильной группы алкильного заместителя.

ИК спектр соединения 6 содержит полосы в области 3208 - $3075 \mathrm{~cm}^{-1}$, характеризующие колебания связей C-H бензольных колец изоиндольных фрагментов, полосы при 2926, 2854 и $1467 \mathrm{~cm}^{-1}$ соответствуют колебаниям связей C-H алкильного остатка, а полоса, характеризующая колебания карбонильных групп, находится при $1697 \mathrm{~cm}^{-1}$.

Электронный спектр поглощения порфирина 6 (Рисунок 5, 1) содержит полосу Соре при 427 нм и полосу $Q$ при 626 нм. Таким образом, аннелирование одного из изоиндольных фрагментов не приводит к сколько-нибудь существенному изменению положения полос поглощения по сравнению с их положением в спектре незамещенного цинктетрабензопорфирина. ${ }^{[16]}$ С другой стороны, несимметричное строение молекулы 6 приводит к появлению в спектре поглощения полос переноса заряда от $\pi$-электроноизбыточного макроцикла тетрабензопорфирина на фрагмент $N$-октилмалеоимида, являющийся акцептором электронов. Эти полосы незначительной интенсивности проявляются при 456 и 668 нм. Кроме того, возрастает и относительная интенсивность полосы $Q$. Если в электронном спектре поглощения тетрабензопорфирината цинка соотношение интенсивностей полос Соре и $Q$ равно 1:0,34, ${ }^{[17]}$ то в спектре соединения 6 оно изменяется до 1:0,40.

Обработкой комплекса $\mathbf{6}$ концентрированной серной кислотой был получен моно[5,6-(2-октил1,3-диоксоизоиндолино]трибензопорфирин (7). Он также представляет собой порошок темно-зеленого цвета, хорошо растворимый в органических средах. В его электронном спектре поглощения (Рисунок 5, 2) наблюдается характерное для незамещенного тетрабензопорфирина расщепление полосы Соре на две компоненты и полосы $Q$ на четыре. Максимумы

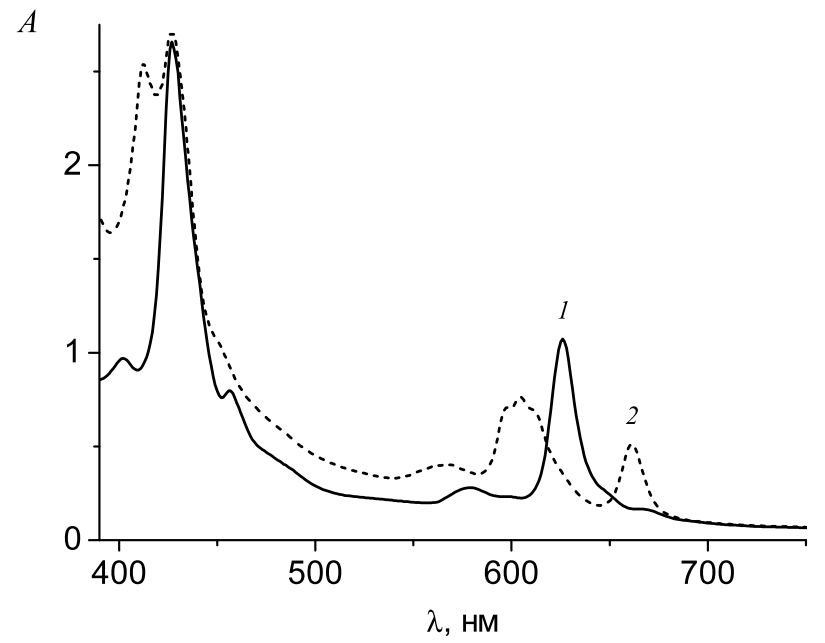

Рисунок 5. Электронные спектры поглощения комплекса 6 (1) и лиганда 7 (2) в толуоле. 


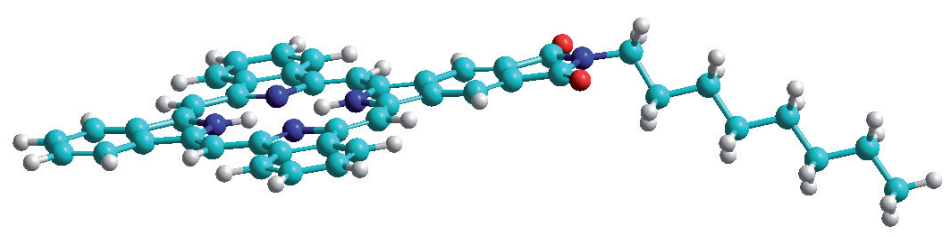

Рисунок 6. Геометрическое строение соединения 5 по данным метода AM1.

полос поглощения находятся в тех же областях, что и в спектре тетрабензопорфирина. ${ }^{[17]}$

Известно, что введение в молекулу металлокомплексов мезо-тетрафенилтетрабензопорфирина восьми акцепторных карбоксиметильных групп приводит к батохромному сдвигу полос поглощения на 10-20 нм, что объясняется увеличением искажения молекул порфиринов, что подтверждено методом РСА. ${ }^{[18]}$ Отсутствие сколько-нибудь значительного влияния аннелированного гетероциклического фрагмента на электронные спектры поглощения соединений 6 и 7 можно объяснить его малым влиянием на геометрию молекул. Квантово-химические расчеты молекулы порфирина 7 (Рисунок 6), выполненные полуэмпирическим методом AM1, подтверждают это предположение.

Как следует из полученных данных, молекула 5 действительно имеет планарное строение, а углы выхода изоиндольных фрагментов из плоскости, задаваемой внутрициклическими атомами азота, не превышают $1,5^{\circ}$.

\section{Заключение}

Таким образом, установлено, что алкилирование 4,5-дикарбоксифталилгидразида алкилбромидом в ДМФА в присутствии поташа приводит к образованию $N, N$ - и $N, O$-диакилзамещенных в соотношении $1: 1$. На основе $N, N$-диалкилзамещенных синтезированы тетрабензопорфирины, содержащие аннелированные фрагменты $N$-октилмалеоимида. Их присутствие обусловливает высокую растворимость полученных порфиринов в органических средах и не оказывает существенного влияния на их электронно-оптические свойства.

Благодарность. Работа выполнена при финансовой поддержке РФФИ (грант № 07-03-00427).

\section{Список литературы}

\section{References}

1. Stuzhin P.A., Bauer E.M., Ercolani C. Inorg. Chem. 1998, 37, 1533-1539.

2. Bauer E.M., Ercolani C., Galli P., Popkova I.A., Stuzhin P.A. J. Porphyrins Phthalocyanines 1999, 3, 371-380.

3. Galanin N.E., Shaposhnikov G.P. Zh. Org. Khim. 2009, 45, 699-704 (in Russ.).

4. Donzello M.P., Ercolani C., Gaberkorn A.A., Kudrik E.V., Meneghetti M., Marcolongo G., Rizolli C., Stuzhin P.A. Chem. Eur. J. 2003, 9, 4009-4024.

5. Donzello M.P., Dini D., D’Arcangelo G., Ercolani C., Ou Z., Zhan R., Stuzhin P.A., Kadish K.M. J. Am. Chem. Soc. 2003, 125, 14190-14204.

6. Yeow E.K.L., Sintic P.J., Cabral N.M., Reek J.N.H., Crossley M.J., Ghiggino K.P. Phys. Chem. Chem. Phys. 2000, 2, 42814291.

7. Kim J.H., Jaung J.Y. Dyes and Pigments 2008, 77, 474-477.

8. Lash T.D., Gandhi V. J. Org. Chem. 2000, 65, 8020-8026.

9. Galanin N.E., Shaposhnikov G.P. Zh. Org. Khim. 2007, 43, 1085-1091 (in Russ.)

10. Eu S., Hayashi S., Umeyama T., Matano Y., Araki Y., Imahori H. J. Phys. Chem. C. 2008, 112, 4396-4405.

11. Kopranenkov V.N.-, Luk'yanets E.A. Izv. Ross. Akad. Nauk, Ser. Khim. 1995, 12, 2320-2336 (in Russ.).

12. Rowe F.M., Peters A.T. J. Chem. Soc. 1933, 1331-1335.

13. Blanksma J.J., Bakels H.A. Rec. Trav. Chim. 1939, 58, 497513.

14. Kopranenkov V.N., Makarova E.A., Luk'yanets E.A. Khim. Geterotsikl. Soed. 1988, 4, 480-484 (in Russ.).

15. Kopranenkov V.N., Dashkevich S.N., Luk'yanets E.A. Zh. Obshch. Khim. 1981, 51, 2513-2517 (in Russ.).

16. Remy D.E. Tetragedron Lett. 1983, 24, 1451-1454.

17. Berezin D.B., Toldina O.V., Kudrik E.V. Zh. Obshch. Khim. 2003, 73, 1383-1389 (in Russ.).

18. Finikova O.S., Cheprakov A.V., Beletskaya I.P., Carrol P.J., Vinogradov S.A. J. Org. Chem. 2004, 69, 522-535.

Received 19.10.2009

Accepted 10.03.2010

First published on the web 20.03.2010 